\title{
GEOLOGIA E EVOLUÇÃO DO SISTEMA DE BACIAS TAFROGÊNICAS CONTINENTAIS DO SUDESTE DO BRASIL
}

\author{
MÁRIO SÉRGIO DE MELO*, CLĀUDIO RICCOMINI*, YOCITERU HASUI*, \\ FERNANDO FLÁVIO MARQUES DE ALMEIDA* e ARMANDO MÁRCIO COIMBRA**
}

\begin{abstract}
The São Paulo, Taubaté, Resende and Volta Redonda basins are filled by similar continental sedimentary sequences. These sequences include a basal rudaceous facies which grades to the top and laterally to a fluviatil facies; only at the Taubaté basin a lower lacustrine facies is present. Palinologic and $\mathrm{K}-\mathrm{Ar}$ datings of ankaramitic flows indicated the Upper Eocene age of the sequences. The basins are hemi-grabens and small faults cutting the sediments are observed. The normal, reverse and strike-slip faults may be related to a regional deformation system with principal NNW-SSE elongation, vertical shortening and ENE-WSW intermediate axis. This deformation may be related to a crustal extension regime or a horizontal dextral displacement. The development of the basins has been linked to the late stage of the Atlantic opening, but intraplate processes are not to be discarded.
\end{abstract}

INTRODUÇÃo O sistema de bacias tafrogênicas continentais do Sudeste do Brasil, denominado "Sistema de Rifts da Serra do Mar" por Almeida (1976), compreende quatro bacias principais de idade terciária (São Paulo, Taubaté, Resende e Volta Redonda, de SW para NE). Elas estão dispostas sobre uma faixa de orientação geral $\mathrm{E}-\mathrm{NE}$, paralela à linha de costa atual (Fig. 1).

Vários estudos já foram realizados em particular sobre a tectônica e a sedimentação desse sistema de bacias. Trabalhos de síntese foram apresentados por Almeida (1976), Hasui et al. (1978) e Asmus \& Ferrari (1978). Entretanto, diversos aspectos permanecem ainda mal conhecidos ou controvertidos, como a idade e a correlação dos depósitos contidos nas diversas bacias; a ligação genética e cronológica com os processos de abertura do Atlântico Sul; e a evolução tectônica do sistema e sua relação com a fraca mas não desprezível sismicidade atual na região.

Face a esses problemas, entre 1982 e 1984 o Instituto de Pesquisas Tecnológicas do Estado de São Paulo (IPT), realizou estudos geológicos na região das bacias de Resende, Volta Redonda e parte das bacias de Taubaté e São Paulo. $\mathrm{O}$ objetivo desses estudos foi a definição da estratigrafia, estruturas e evolução tectônica das bacias, sua interrelação $\mathrm{e}$ com o sistema como um todo. No caso da Bacia de São Paulo, visou-se estudar alguns dos depósitos cortados por falhas ali existentes, estabelecendo-se a extensão e a origem desses falhamentos.

Os resultados foram objeto de dois relatórios técnicos de difusão restrita (Melo et al. 1983, Almeida et al. 1984a). A finalidade deste trabalho é apresentar algumas considerações emergentes desses estudos sobre a evolução das bacias tafrogênicas.

PROBLEMÁTICA ATUAL Admite-se hoje consensualmente que a origem do sistema de bacias é consequêencia da abertura do Atlântico Sul, mas não existe uma opinião unânime sobre os mecanismos de evolução e a cronologia relativa dos eventos.

Almeida (1976) considera que o sistema de bacias desenvolveu-se sobre o eixo de arqueamento na borda do conti- nente. Este arqueamento resultaria de uma movimentação vertical ascendente em oposição ao abatimento da bacia de Santos, situada na plataforma continental adjacente. Para este autor, a região teria sido submetida a três pulsações tectônicas. Na primeira, entre o Senoniano e o Paleoceno, grande atividade tectônica teria ocorrido na região da Serra do Mar, acompanhada de vulcanismo alcalino. Na segunda, iniciada no Oligoceno, ter-se-ia formado a bacia de Taubaté, e ali se depositado a Formação Tremembé. A terceira, provavelmente durante o Plioceno, teria ensejado o advento da Bacia de São Paulo, preenchida pela formação homônima, enquanto a subsidência nas bacia de Taubaté e Resende ter-se-ia acelerado com deposição de sedimentos clásticos continentais.

Asmus \& Ferrari (1978) consideram o sistema de bacias como um conjunto de semigrabens ligados ao basculamento para NW de blocos sobre a borda elevada da bacia de Santos. Esses autores propõem um esquema evolutivo considerando uma relação genética entre a bacia de Santos e o sistema de bacias continentais, mas com uma importante defasagem de tempo. Este modelo implica admitir-se o desenvolvimento de falhas na borda da Bacia de Santos só durante o Oligoceno, enquanto as demais bacias da plataforma continental brasileira são, geralmente, do Cretáceo Superior (Ponte \& Asmus 1976, Asmus \& Guazelli 1981).

$\mathrm{Na}$ realidade, esses autores tentam propor um esquema coerente para explicar a diferença de idade entre a abertura do Atlântico Sul e a formação do sistema de hacias tafrogênicas continentais, com estes dois eventos supostamente ligados às mesmas causas.

Entretanto a própria idade admitida para a formação das bacias tafrogênicas (idade dos mais antigos depósitos terciários) tem sido colocada em questão a partir dos resultados mais recentes. Se os primeiros autores (v.g. Moraes Rego 1932) consideraram que os depósitos seriam pliocênicos ou pleistocênicos, atualmente já se tem verificado idade eocênica superior à oligocênica para estes sedimentos.

CONTEXTO GEOLOGICO REGIONAL O sistema de bacias tafrogênicas situa-se na região do Planalto Atlântico

* Instituto de Pesquisas Tecnológicas do Estado de São Paulo - IPT, Cidade Universitária Armando de Salles Oliveira - Cx. Postal 7141, CEP 01000 São Paulo, SP, Brasil.

** Instituto de Geociências, Cidade Universitária Armando de Salles Oliveira, USP, CEP 05508, São Paulo, SP, Brasil. 
nos estados de São Paulo e Rio de Janeiro, distando em média $80 \mathrm{~km}$ da linha de costa. A altitude do topo dos sedimentos terciários (que são nivelados por superfícies de erosão elaboradas no Neogeno e Quaternário) varia de $800 \mathrm{~m}$ na Bacia de São Paulo a $450 \mathrm{~m}$ na de Volta Redonda.

Os traços mais marcantes do relevo da região são as serras do Mar e da Mantiqueira, extensas escarpas de linhas de falhas formadas pelos mesmos processos que originaram as bacias. $\mathrm{O}$ desnivelamento médio de cada uma das serras é da ordem de $1.000 \mathrm{~m}$ e chegam a quase $2.000 \mathrm{~m}$ em alguns casos.

A principal linha de drenagem da região é o Rio Paraíba do Sul, que tem suas nascentes (rios Paraibuna e Paraitinga) na Serra da Bocaina, ao sul da Bacia de Resende. Daí, este rio se dirige inicialmente para SW e muda bruscamente seu curso à altura da soleira que separa as bacias de Taubaté e São Paulo, o que sugere fenômenos de captura ligada à atividade tectônica. O Paraíba do Sul toma em seguida o curso E-NE, atravessando as bacias de Taubaté, Resende e Volta Redonda antes de se lançar ao mar, mais a norte.

A Bacia de São Paulo é hoje drenada pelo curso superior do Rio Tietê, afluente do Paraná.

O embasamento das bacias é representando por rochas cristalinas pré-cambrianas polideformadas, com estruturas complexas. Essas rochas foram cortadas por importantes falhas transcorrentes de direção E-NE no Cambro-Ordoviciano e também por juntas subverticais de origem tardia no Ciclo Brasiliano, as quais normalmente configuram quatro famílias, uma paralela/subparalela, uma normal/subnormal e duas oblíquas à foliação das rochas metamórficas (Hasui et al. 1982). As falhas E-NE influenciaram a localização das falhas normais da reativação no Mesozóico-Cenozóico assim como as juntas constituíram anisotropias que favorecem o alívio dos novos sistemas de tensões.

A região de exposição do embasamento que abriga as bacias tafrogênicas é localizada entre a bacia intracratônica do Paraná, a W-NW, e a Bacia de Santos, na plataforma continental a SE (Fig. 1). Essa região foi submetida a arqueamento e forte erosão a partir do final do Paleozóico até o início dos processos de ruptura continental, no Jurássico Superior. Esse arqueamento pré-rift manifestou-se na zona costeira, mas também ao longo do Arco de Ponta Grossa, uma região àquela época tectonicamente positiva, de direção NW. Falhas normais a NW são encontradas ao longo deste arco. Arqueamentos ocorreram com menor expressão também ao longo dos lineamentos de Guapiara e do Piqueri (Ferreira 1982).

$\mathrm{Na}$ zona off-shore da região do sistema de bacias tafrogênicas, contata-se a existência de uma estrutura transversal, indicada sobretudo por inflexões de linhas batimétricas (Asmus 1978). Esta estrutura, denominada "Lineamento do Rio de Janeiro" (Asmus \& Guazelli 1981), seria associada à zona de fratura oceânica. Ela não é marcada na plataforma continental, mas sua atividade tem sido relacionada com algumas feições, como o alto que separa as bacias de Campos e de Santos, o alinhamento de intrusões alcalinas entre Cabo Frio e Poços de Caldas, e a inflexão da linha costeira em Cabo Frio (Fig. 1). Asmus (op. cit.) admite até mesmo que o prolongamento do alinhamento oceânico para o continente poderia apresentar ramificações, responsáveis até pelas soleiras que separam as bacias tafrogênicas continentais.

As manifestações magmáticas associadas aos processos de ruptura continental são representadas por vulcanismo bási- co seguido pela intrusão de maciços de rochas, sobretudo alcalinas. $\mathrm{O}$ vulcanismo básico é representado pelos derrames basálticos da Formação Serra Geral da Bacia do Paraná e por enxames de diques de direção predominante NW sobre o Arco de Ponta Grossa e lineamente de Guapiara e do Piqueri, e de direção E-NE ao longo da costa entre São Paulo e Rio de Janeiro. Os maciços de rochas alcalinas distribuem-se de modo algo disperso, mas se concentram principalmente na região de influência do Arco de Ponta Grossa e do Lineamento de Guapiara, e, de modo mais proeminente, ao longo de uma faixa W-NW entre Cabo Frio e Poços de Caldas (Fig. 1).

A atividade sísmica atual da região das bacias tafrogênicas não é desprezível. Em alguns casos, os sismos atingem magnitude 5 . Os epicentros não mostram concentrações muito nítidas, o que tem levado a certas divergências nas propostas de zoneamento sísmico bem como a uma atualização constante dessas proposições. Estudos da Universidade de Brasília (1979) conduziram à delimitação de quatro regiões de maior atividade sísmica: nordeste do Estado de São Paulo; norte do Rio de Janeiro e sul do Espírito Santo; região de Cananéia a Florianópolis; e região de direção aproximadamente E-W ao longo do Rio Grande (MG-SP) e do lineamento de intrusões alcalinas. Sadowski \& Dias Neto (1981) definem o "Lineamento sismo-tectônico de Cabo Frio", estendendo-o de Cabo Frio a Poços de Caldas, com sismicidade preferencial ao longo de sua trajetória. Hasui et al. (1982) demarcam, em caráter preliminar, seis zonas sismogênicas: Bom Sucesso, localizada na borda da Província São Francisco; Pinhal, na área de soerguimento de Moji-Guaçu, a NE do Estado de São Paulo; Caxambu, no sul de Minas Gerais; Cunha, acompanhando a região costeira entre Santos e Rio de Janeiro; Cabo Frio, na plataforma continental; e Campos, no limite entre Rio de Janeiro e Espírito Santo. Mioto (1984), além de admitir praticamente as mesmas zonas sismogênicas de Hasui et al. (op. cit.), refere-se ainda à existência de uma sétima, denominada Cananéia ou Paranaguá. De maneira genérica, entretanto, observa-se que os epicentros apresentam tendência de concentração na zona costeira adjacente à Bacia de Santos, sobre o limite da Província Tectônica do São Francisco, e também ao longo do alinhamento de maciços alcalinos de direção E-W a WNW.

$\mathrm{Na}$ linha de costa da região existem setores com comportamento tectônico atual diferenciado (Suguio \& Martin 1976). Alguns são mais positivos, com conseqüente acumulação de extensões mais vastas de sedimentos quaternários ao longo da costa, como é o caso ao norte do paralelo $23^{\circ} \mathrm{S}$ e ao sul do paralelo 240 S. Já entre os paralelos 230 e $240 \mathrm{OS}$ constata-se um comportamento negativo, com tendência à imersão. Esse comportamento diferenciado, bem como a sismicidade atual, indica uma atividade tectônica residual significativa na região.

Cabe ainda lembrar que, além das quatro bacias principais aqui citadas, alguns autores (Almeida 1976, Hasui et al. 1978) consideram outras depressões no contexto do sistema de bacias tafrogênicas, como é o caso do "Rift da Guanabara" e da Bacia de Curitiba. Neste trabalho preferiu-se não analisar essas depressões em conjunto com as demais até que estudos de maior detalhe esclareçam melhor as relações tectônicas e cronológicas entre elas.

SISTEMA DE BACIAS TAFROGENICAS As quatro 

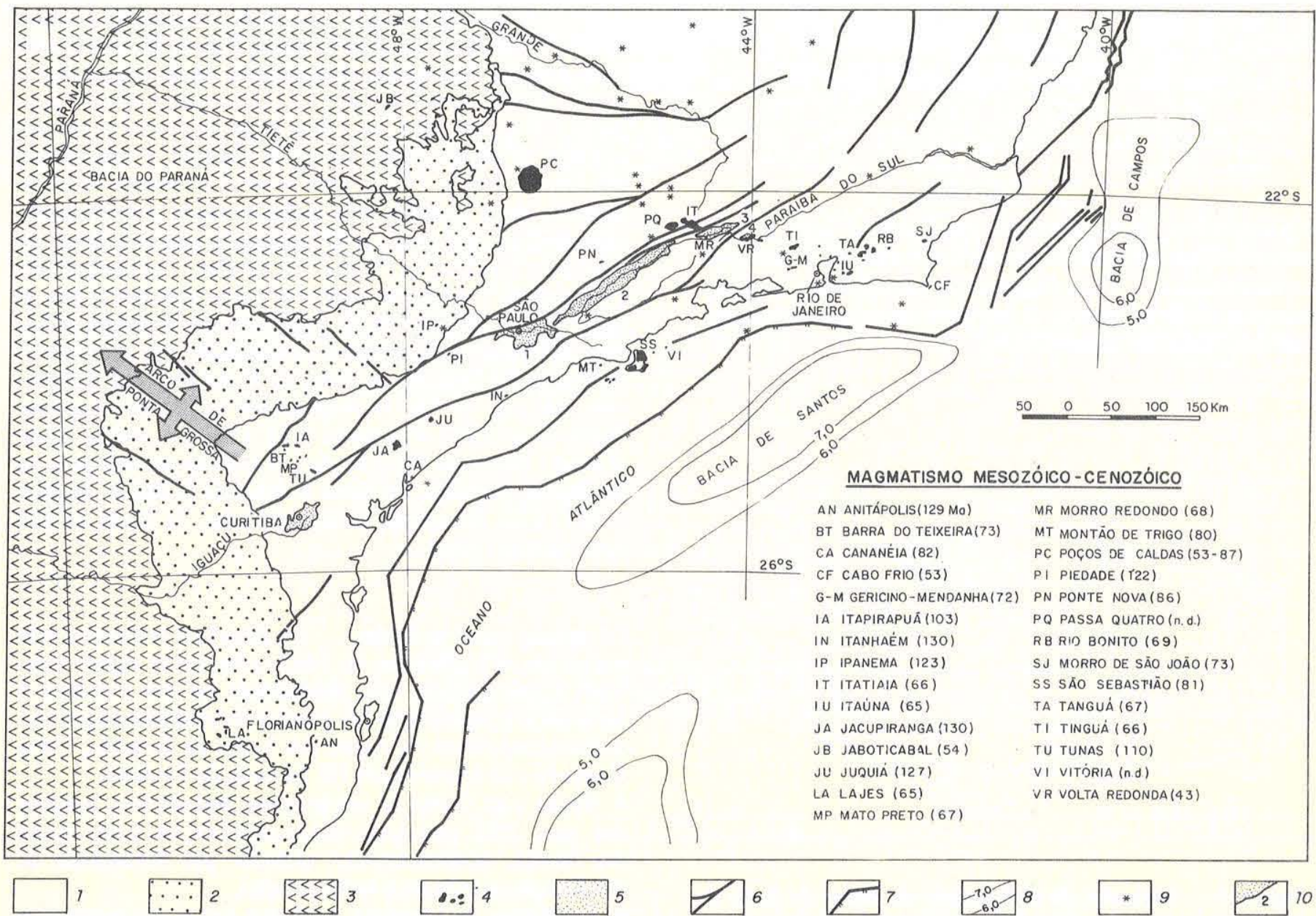

Figura 1 - Estrutura regional e magmatismo mesozóico-cenozóico na Região Sudeste do Brasil: 1. embasamento pré-cambriano; 2. sedimentos paleozóicos e mesozóicos da bacia do Paraná; 3. derrames basálticos da Formação Serra Geral e coberturas cretáceas; 4. rochas magmáticas mesozóico-cenozóicas; 5. sedimentos terciários; 6. falhas principais; 7. zonas de flexura; 8. isópacas das bacias da plataforma continental (em km); 9. epicentros de sismos; 10. localização das bacias terciárias: 1. São Paulo; 2. Taubaté; 3. Resende; 4. Volta Redonda (compilado de Schobbenhaus Fo. et al. 1981; Ulbrich \& Gomes 1981; Hasui et al. 1982)

bacias principais do sistema distribuem-se sobre uma distância total de mais de $300 \mathrm{~km}$. Os blocos de falhas normais que acolhem as depressões tectônicas estão inclinados para NW. As bacias continentais encontram-se em sítios particulares (limite NW dos blocos). Além disso, as bacias de Taubaté (Hasui \& Ponçano 1978) e de Resende (Melo et al. 1983) colocam em evidência esta inclinação para NW por suas características de semi-grabens (variação de espessuras dos sedimentos, inclinação das camadas, morfologia do substrato e distribuição de fácies sedimentares). A Bacia de São Paulo, apesar de sua estrutura mais complexa, apresenta também claro espessamento das camadas em direção ao norte (Hasui \& Carneiro 1980).

Distinguem-se três tipos de fácies sedimentares de idade terciária nas bacias do sistema (Figs. 2 e 3):

- Uma fácies predominantemente lacustre com argilas verdes (esmectitas), mais bem desenvolvida nos compartimentos mais internos da Bacia de Taubaté (Formação Tremembé, de Almeida 1958);

- Uma fácies fanglomerática (brechas e conglomerados polimíticos com matriz lamítica e arenosa), mais bem desenvolvida na borda norte das bacias, sobretudo de Taubaté e Resende. Esta fácies resulta da coalescência de leques aluviais ligados aos importantes escarpamentos tectônicos (Amador 1975; Hasui \& Ponçano 1978; Melo et al. 1983);

- Uma fácies fluvial com sedimentos de granulação variada e notável imaturidade textural e mineralógica. Esta fácies aparece sob a forma de depósitos de sistema fluvial anastomasado nas bacias de São Paulo (Coimbra et al. 1983) e Volta Redonda (Amador \& Castro 1976, Melo et al. 1983), e também sob a forma de depósitos de sistema meandrante com planícies de inundação, na área da Bacia de São Paulo (Suguio 1980).

Os depósitos de sistema fluvial anastomosado presentes nas diversas bacias foram originalmente descritos por vários autores, que nem sempre admitiram correlação e contemporaneidade entre eles. Entretanto os resultados de estudos mais recentes têm demonstrado o sincronismo desses depósitos, todos do Paleogêneo. Os depósitos de sistema fluvial anastomosado presentes na Bacia de Taubaté (Suguio 1969) receberam a denominação de Formação Caçapava (Carneiro et al. 1976), considerada interdigitada com a parte superior da Formação Tremembé (Hasui \& Ponçano 1978). Na Bacia de São Paulo, esses depósitos são representados por unidade tida até recentemente como sendo quaternária (Formação 


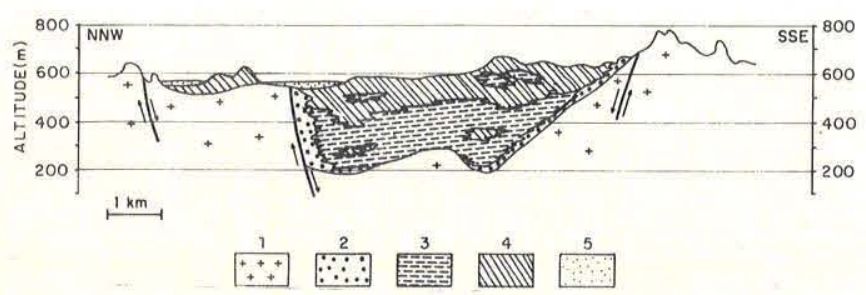

Figura 2 - Seção esquemática transversal à Bacia de Taubaté na região de Jacarei-São José dos Campos: 1. pré-cambriano indiviso; 2. fácies marginal (fanglomerática); 3. fácies lacustre; 4. fácies fluvial; 5. aluviões quaternários (modificado de Hasui \& Ponçano 1978)

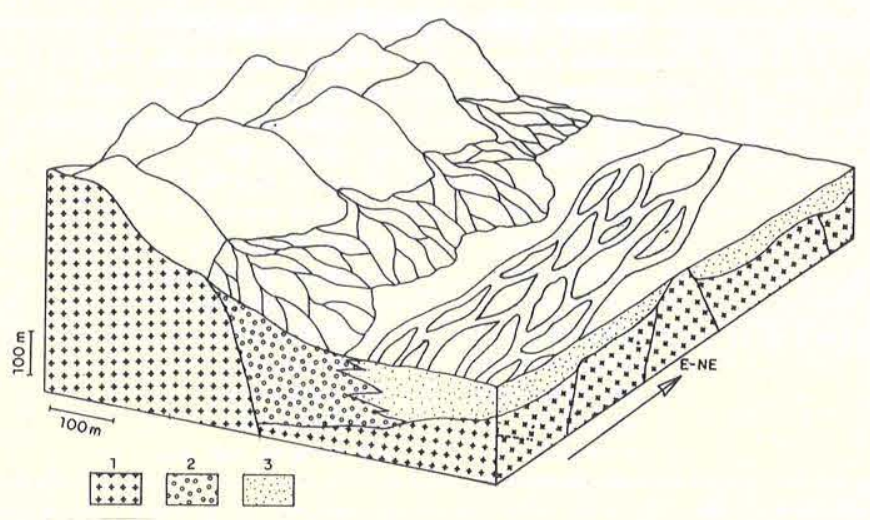

Figura 3 - Esquema da distribuição de fácies da Bacia de Resende: 1. embasamento pré-cambriano; 2 fácies rudácea (fanglomerática); 3. fácies fluvial (Melo 1984)

Itaquaquecetuba, de Coimbra et al. 1983) e, atualmente, considerada como terciária (Melo 1984). A denominação Formação Resende é empregada para os sedimentos de sistema fluvial anastomosado que preenchem a bacia homônima (Amador 1975) e a de Volta Redonda (Melo et al. 1983).

Os depósitos de sistema fluvial meandrante com planícies de inundação da Bacia de São Paulo foram originalmente denominados Formação São Paulo (Moraes Rego 1930, Mezzalira 1962). Estudos em andamento na área dessa bacia e extremidade contígua da Bacia de Taubaté (realizados por diversas entidades) têm mostrado que, nos dois locais, existiram depósitos basais de sistema fluvial anastomosado, que passam em direção ao topo para depósitos de sistema meandrante argiloso. Esta sucessão constitui uma nova proposição da relação entre as formações Itaquaquecetuba e São Paulo, no conjunto correlacionáveis à Formação Caçapava.

Em todas as quatro bacias, o topo original dos depósitos foi cortado por superfícies de erosão de idade neogênica a quaternária. As espessuras máximas de sedimentos atualmente conhecidas são de mais de $520 \mathrm{~m}$ na Bacia de Taubaté, $320 \mathrm{~m}$ em São Paulo, $200 \mathrm{~m}$ em Resende e $100 \mathrm{~m}$ em Volta Redonda.
A idade da sedimentação é indicada por datações realizadas nos depósitos das quatro bacias. Fósseis de mamíferos da Formação Tremembé apresentaram idade oligocênica e miocênica (Couto \& Mezzalira 1971) enquanto estudos palinológicos de um nível um pouco mais profundo da mesma unidade acusaram idade eocênica superior à oligocênica (Ferreira \& Santos 1982). Outros estudos também na parte superior desta unidade têm indicado idade possivelmente oligocênica (Lima et al. 1983) enquanto para os linhitos de depósitos contidos na "Bacia" de Bonfim, correlacionáveis à Formação Tremembé, obteve-se idade eocênica (Lima \& Dino 1985). Datações K-Ar efetuadas em derrames de rochas vulcânicas ankaramíticas intercaladas nos sedimentos da Formação Resende na Bacia de Volta Redonda forneceram idade de $43 \mathrm{Ma}$, correspondente ao Eoceno Superior (Melo et al. 1983, Riccomini et al. 1983). A mesma idade (Eoceno Superior) foi indicada por análises palinológicas na Formação Resende, da bacia homônima (Lima \& Amador 1983), e na Formação Itaquaquecetuba, da Bacia de São Paulo (Melo 1984).

Correlação entre as Bacias Os trabalhos realizados pela equipe do IPT (Melo et al. 1983) adiantaram alguns argumentos que indicam uma similaridade no que concerne à natureza e à cronologia dos eventos tecto-sedimentares mesozóico-cenozóicos na região das bacias de Resende, Volta Redonda e da extremidade NE da bacia de Taubaté:

- Bacias com forma de semigrabens, assimétricas, basculadas para NW; principais falhas normais na borda norte das bacias, ocasionalmente afetadas por fenômenos de silicificação anteriores à sedimentação;

- Evidências de atividade tectônica sin- e pós-sedimentar (sedimentos basculados e afetados por falhas);

- Presença das mesmas fácies sedimentares (fanglomerática e fluviàl), com uma distribuição análoga nas bacias (mesmas litologias e estruturas sedimentares);

- As três bacias apresentam um padrão comum de distribuição de espelhos de falha e estrias, que revela uma similaridade quanto à posição dos eixos principais de deformação geral e de esforços: estiramento máximo NNW, eixo intermediário ENE e eixo de encurtamento máximo vertical (Campanha et al. 1985).

Esses argumentos indicam que a Formação Caçapava da Bacia de Taubaté e a formação Resende das bacias de Re sende e Volta Redonda apresentam correlação cronológica e genética. Isto é confirmado pelas idades obtidas para esses depósitos, todas compreendidas entre o Eoceno Superior e o Oligoceno.

$\mathrm{Na}$ área da Bacia de São Paulo, a Formação Itaquaquecetuba apresenta também uma analogia genética e cronológica com as formações fluviais terciárias das demais bacias. De acordo com os resultados dos estudos em andamento, o conjunto representado pelas formações Itaquaquecetuba e São Paulo seria correlacionável litológica e cronologicamente aos depósitos englobados na Formação Caçapava no extremo SW da Bacia de Taubaté.

Além disso, nas áreas das bacias de Resende, Volta Redonda (Melo et al. 1983) e Taubaté (Suguio 1969, Hasui \& Ponçano 1978) observam-se importantes falhas normais E-NE longitudinais ao alongamento das bacias e também falhas transversais ou oblíquas, estas responsáveis pela formação de soleiras e uma compartimentação em sub-bacias. 
$\mathrm{Na}$ área de Resende, as falhas oblíquas têm direção NNE, distinguindo-se ainda duas outras direções subordinadas de falhas, NNW e WNW (Melo 1984). Dois sistemas principais de falhas, E-NE e N-NW, foram encontrados também na área de definição da Formação Itaquaquecetuba na Bacia de São Paulo (Coimbra et al. 1983, Almeida et al. 1984a e 1984b). A análise do padrão de distribuição dessas falhas indica para a Bacia de São Paulo uma orientação dos principais eixos de deformação geral e de esforços deduzidos semelhante àquele definido na área das bacias de Resende e Volta Redonda, e extremidade NE da Bacia de Taubaté (Campanha et al. 1985).

Esses dados indicam similaridade quanto aos processos formadores das bacias de São Paulo, Taubaté, Resende e Volta Redonda. Parece viável, o que ainda não foi comprovado, que a extensão original dos sedimentos tenha sido muito maior, com possível ligação geográfica entre as bacias, que teriam sido separadas posteriormente pela atividade ao longo das falhas transversais ou oblíquas e erosão subseqüentes.

Esta suposição é sugerida pelas características da "Bacia" de Bonfim, uma pequena ocorrência de sedimentos terciários contendo linhitos, preservada numa depressão tectônica embutida em rochas pré-cambrianas ao sul de Caçapava, isolada dos sedimentos da Bacia de Taubaté por uma faixa de rochas do embasamento com 2-3 km de largura. Estudos palinológicos desses sedimentos indicaram idade eocênica, o que levou Lima \& Dino (1985) a considerá-los correlativos dos níveis basais da Bacia de Taubaté, com os quais possivelmente apresentariam continuidade lateral, uma vez que as características do linhito sugerem que o mesmo esteve submetido a condições de uma profundidade considerável, e as características dos sedimentos não são típicas de borda de bacia. A ocorrência de Bonfim poderia representar, assim, um testemunho da maior extensão original dos sedimentos da Bacia de Taubaté, preservada da erosão subseqüente pelo embutimento tectônico.

A Formação Tremembé, situada na base dos depósitos da Bacia de Taubaté, parece mais difícil de ser interpretada. As datações nela realizadas realizaram-se no topo da unidade, pelo menos $200 \mathrm{~m}$ acima de sua base. Parece factível que esta unidade seja resultado de um brusco barramento tectônico da drenagem, com formação de um lago e deposição de finos na parte central, onde uma fácies flanglomerática se teria depositado nas margens, principalmente na borda NW, onde a movimentação de falhas teria sido acentuada. É possível que este barramento e o início da sedimentação na bacia de Taubaté se tenham dado mais cedo que nas demais bacias, o que encontra suporte nos resultados de estudos palinológicos de Wickert (1974), que interpreta os gêneros encontrados em profundidades entre 50 e $85 \mathrm{~m}$ (maiores que as estudadas por outros autores) como sendo do Terciário Inferior e do Cretáceo Superior, sugerindo idade pelo menos terciária inferior para esses sedimentos.

\section{Evolução Mesozóico-Cenozóica e Ruptura Continen-} tal $\mathrm{O}$ arqueamento que precedeu a ruptura continental e formação do Atlântico na Região Sudeste do Brasil é indicado pela atividade tectônica ao longo do Arco de Ponta Grossa. No Triássico-Jurássico, o soerguimento ao longo do arco separa duas sub-bacias. Ao norte, deposita-se a Formação Pirambóia enquanto ao sul deposita-se o Grupo Rosário do Sul.
O magmatismo basáltico (Formação Serra Geral na Bacia do Paraná e feixes de diques) marca o início do desenvolvimento de fraturas de distensão nos eixos do arqueamento (Herz 1977, Herz 1978, Asmus 1978). Esta manifestação corresponde ao magmatismo pré-rift de Sengor \& Burke (1978) e Baker \& Morgan (1981).

É provável que ao final desta fase magmática (que perdurou entre 147 e $119 \mathrm{Ma}$, segundo Amaral et al. 1966) tenha tido lugar o desenvolvimento das falhas normais de grande rejeito, entre elas as que deram origem às serras do Mar e da Mantiqueira. Ao mesmo tempo, no embrião da Bacia de Santos, então uma depressão de rift recém-formada (Herz 1977), depositaram-se os sedimentos continentais da Formação Guaratiba (Ponte \& Asmus 1976).

Magmatismo alcalino de tipo central com tendência básica (Ulbrich \& Gomes 1981), contemporâneo do magmatismo basáltico (130 a 122 Ma, segundo Amaral et al. 1967), manifestou-se em duas regiões bem definidas. Uma é representada pelo Maciço de Anitápolis (Santa Catarina) e a outra, pelo Maciço de Jacupiranga (São Paulo) e maciços vizinhos. Herz (1977 e 1978) considera tais regióes como sendo os nós de junções tríplices, segundo o modelo de Burke \& Dewey (1973). Dois ramos dessas junções, Anitápolis-Jacupiranga e Jacupiranga-Cabo Frio, teriam evoluído em seguida para a zona de ruptura continental enquanto o terceiro ramo, correspondente ao eixo do arco de Ponta Grossa, teria abortado.

As direções dos feixes de diques básicos (NW e NE a ENE), bem como a distribuição das intrusões das rochas alcalinas, são compatíveis com esta hipótese de junções tríplices, embora as falhas NE e ENE, que se associam ao limite atual do continente emerso, estejam muito distantes do limite da crosta continental, que se situaria para além do Platô de São Paulo, a mais de $500 \mathrm{~km}$ da linha de costa atual (Kowsmann et al. 1982). Falhas NW originaram depressões sobre o eixo do Arco de Ponta Grossa, onde espessas colunas de derrames basálticos foram acumuladas (Vieira 1973, Herz 1977).

O magmatismo alcalino que formou os complexos de Itapirapuã e Tunas, situados ainda próximos do nó de Jacupiranga, já poderia estar associado ao processo de separação das placas Sul-Americana e Africana, que segundo Herz (1977 e 1978) se teria iniciado há 112 Ma. Os primeiros depósitos tipicamente marinhos da Bacia de Santos pertencem à mesma época (Aptiano) (Ponte \& Asmus 1976, Asmus \& Guazelli 1981).

Numerosos corpos alcalinos mais jovens, com idades entre 53 e $87 \mathrm{Ma}$, são encontrados ao longo da costa, e também ao longo do Arco de Ponta Grossa e do alinhamento WNW entre Cabo Frio e Poços de Caldas. Tal distribuição de idades não permite propor uma hipótese de origem tectônica simples.

A partir das evidências de migração do pólo de rotação da abertura do Atlântico Sul, há $80 \mathrm{Ma}$ (Bullard et al. 1965, Le Pichon \& Hayes 1971), Marsh (1973) ligou as manifestações magmáticas ao longo do alinhamento WNW a reativações de uma zona de fratura oceânica coincidente com um círculo centrado no novo pólo, e que se estenderia pelo continente.

Herz (1977 e 1978) baseou-se no modelo de evolução de hot-spots para explicar a origem e a distribuição dos maciços alcalinos da zona litorânea de São Paulo e Rio de Janeiro. Tal concepção foi retomada por Sadowski \& Dias Neto 
(1981) em relação ao alinhamento de alcalinas entre Cabo Frio e Poços de Caldas, que estes autores supuseram estar associado ao Lineamento do Rio de Janeiro, da plataforma continental. Entretanto a disposição das rochas alcalinas e suas idades não permitem relacioná-las a modelos simples de evolução de hot-spots. Tal fato já foi observado por Asmus (1978), Asmus \& Guazelli (1981) e Almeida (1983).

Existe outra linha de interpretação para as intrusões alcalinas, que implica complicações em níveis subcrustais ou sublitosféricos a serem consideradas no contexto da deriva da Placa Sul-Americana. Tal linha contempla soerguimento e fortes influências de estruturas crustais preexistentes. Hasui et al. (1982) consideram três soerguimentos regionais em moldes semelhantes ao do Alto Paranaíba (Almeida et al. 1980). Para a "Província da Serra do Mar", Almeida (1983) relacionou os maciços alcalinos à reativação de estruturas E-NE do embasamento paralelas à borda da Bacia de Santos como conseqüência de movimentos verticais opostos entre esta bacia e o bloco continental emerso. Como argumento suplementar, este autor faz referência ao nítido condicionamento estrutural de alguns dos maciços (como o de Gericinó-Mendanha) pelas estruturas E-NE.

Propostas de Modelo Evolutivo para as Bacias Continentais Terciárias A partir das evidências e dos argumentos discutidos, pode-se propor a seguinte seqüência de eventos tectônicos e geológicos, e subseqüente formação do sistema de bacias tafrogênicas continentais (Fig. 4):

- Arqueamento na região do arco de Ponta Grossa e ao longo da atual linha de costa.
- Abertura de fraturas de distensão ao longo do eixo das regiões arqueadas no máximo do soerguimento; formação dos derrames basálticos da Bacia do Paraná (Formação Serra Geral) e da base da coluna da Bacia de Santos, e intrusão dos feixes de diques (predominantemente NW ao longo do Arco de Ponta Grossa e E-NE no litoral entre São Paulo e Rio de Janeiro) (Jurássico Superior e Neocomiano).

- Magmatismo alcalino de tipo central; início da atividade das falhas e rifting ao longo do Arco de Ponta Grossa (ramo abortado de junção tríplice de Herz 1977) e da linha de costa atual; e magmatismo basáltico (final da fase anterior (Neocomiano).

- Sedimentação continental no embrião da bacia de Santos (Formação Guaratibà, no Neocomiano) Ponte \& Asmus 1976).

- Continuidade da atividade das falhas normais paralelas à linha de costa e mais atenuada sobre o Arco da Ponta Grossa.

- Reativação do magmatismo alcalino sobre o arco e sedimentação evaporítica (estádio proto-oceânico) na Bacia de Santos (Aptiano).

- Continuidade dos deslocamentos verticais opostos entre a região emersa e a Bacia de Santos; atividade de falhas normais E-NE ao longo da linha de costa, associada a magmatismo alcalino de tipo central; condicionamento da drenagem da região pelos basculamentos de blocos para N-NW (rios subseqüentes); e sedimentação de plataforma pouco profunda e marinha franca na Bacia de Santos (estádio oceânico, a partir do Albiano).

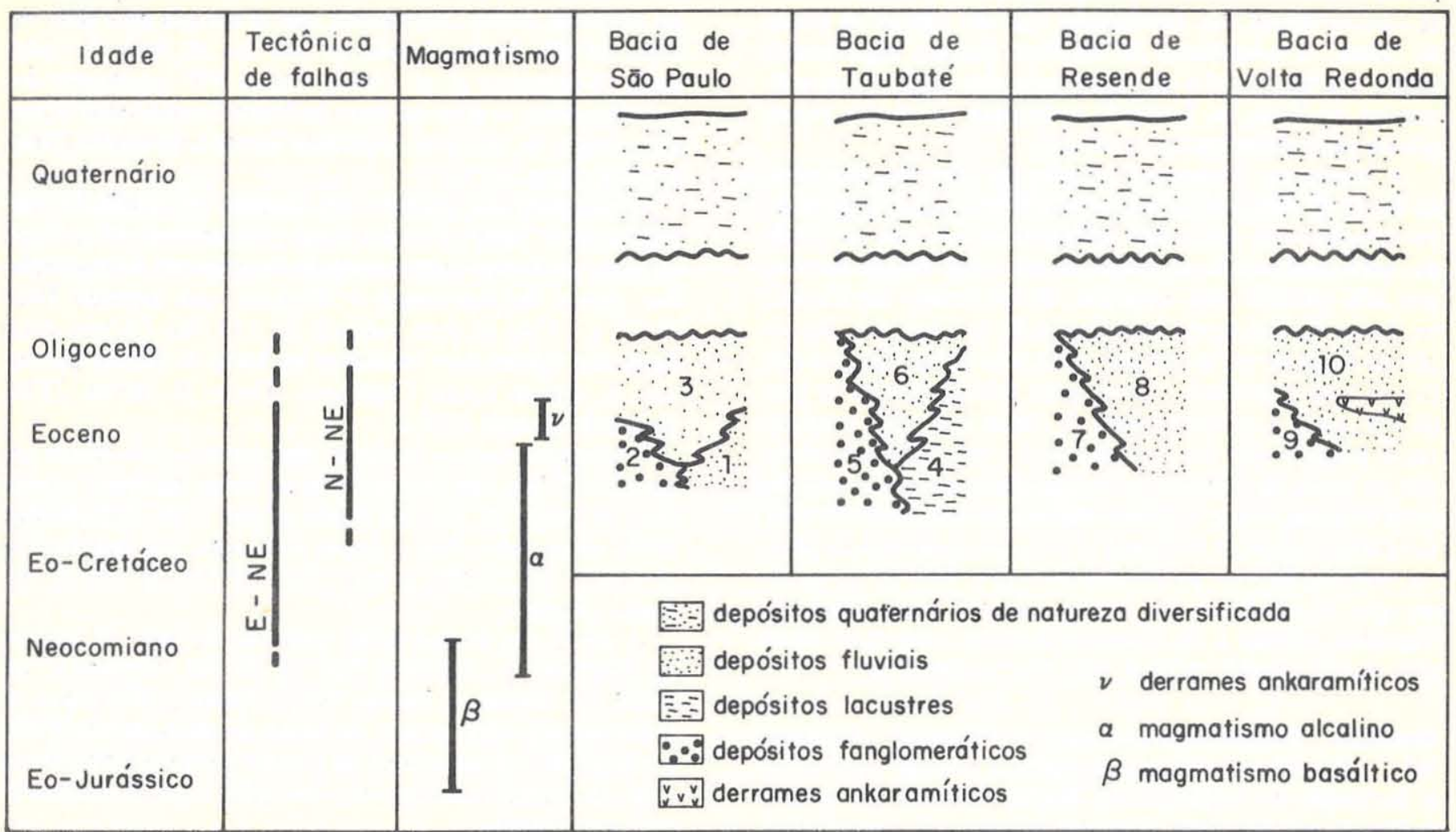

Figura 4 - Comparação entre tectônica, magmatismo e sedimentação nas bacias tafrogênicas. 1. fácies fluvial da Formação Itaquaquecetuba; 2. fácies fanglomerática da Formação Itaquaquecetuba; 3. Formação São Paulo; 4. Formação Tremembé; 5. "fácies marginal" (fanglomerática); 6. Formação Caçapava; 7. fácies rudácea (fanglomerática) da Formação Resende; 8. fácies fluvial da Formação Resende; 9. fácies fanglomerática; 10. fácies fluvial da Formação Resende na bacia de Volta Redonda 
- Deslocamento do pólo de rotação do Atlântico Sul (Santoniano); desenvolvimento de estrutura transversal à margem continental e de falhas normais $\mathrm{N}-\mathrm{NE}$; e continuidade dos movimentos verticais opostos, da atividade de falhas E-NE e do magmatismo alcalino ao longo da costa.

- Barramentos de drenagem de caráter subseqüente e pelas falhas normais $\mathrm{N}-\mathrm{NE}$, então com maior atividade que as falhas E-NE (Eoceno); formação de um paleolago nos compartimentos internos da Bacia de Taubaté com a sedimentação da Formação Tremembé; preenchimento do lago e transição para sistema deposicional fluvial anastomosado, representado pela Formação Caçapava, interdigitada com a porção superior da precedente; sedimentação sincrônica nas bacias de Resente e Volta Redonda (Formação Resende) e também na Bacia de São Paulo (Formação Itaquaquecetuba); derrames ankaramíticos na área da bacia de Volta Redonda (Eoceno Superior); e transição para sistema fluvial meandrante, representado pela Formação São Paulo e pela fácies superior da Formação Caçapava no extremo SW da Bacia de Taubaté (Eoceno Superior-Oligoceno).

- Continuidade da atividade tectônica, mais pronunciada ao longo das falhas $\mathrm{N}-\mathrm{NE}$, mas ainda presente nas falhas paralelas à linha de costa; progressivo enfraquecimento da atividade, com possíveis reativações, sin- e pós-sedimentares; soerguimento regional e erosão pronunciada na região emersa; e atividade residual atual indicada pela fraca sismicidade e pelo comportamento tectônico diferenciado observado ao longo da linha de costa.

O Modelo Tectônico A evolução regional tem sido interpretada em termos de tectônica de distensão crustal, seja ligada a deslocamentos horizontais da Placa Sul-Americana, seja à incidência de movimentos verticais de algum modo vinculados a deslocamentos de massas sublitosféricas. Essa distensão seria tal que o eixo de estiramento máximo se orientaria segundo NW.

A análise das falhas geradas nas bacias de Resende, Volta Redonda, Taubaté e São Paulo permite deduzir que os eixos de deformação se orientam segundo NNW (estiramento máximo), ENE (eixo intermediário) e vertical (encurtamento principal). Tais eixos, em regime de cisalhamento puro, podem ser considerados como coincidentes com $\sigma_{3}, \sigma_{2}, \sigma_{1}$, respectivamente (Campanha et al. 1985).

Uma interpretação alternativa contempla o mecanismo de cisalhamento simples. Levando em conta orientações gerais das falhas e tipos com componentes direcionais de rejeito mais expressivas que componentes de mergulho observados na área da Bacia de Resende, pode-se inferir um binário horizontal W-NW passando por esse local (Melo 1984).

A decisão entre um e outro modelo tectônico requer maior aprofundamento na investigação de falhas e feições decorrentes dos regimes tensionais.

CONCLUSÕES Os estudos recentes relativos às quatro principais bacias (São Paulo, Taubaté, Resende e Volta Redonda) do sistema de bacias tafrogênicas continentais do Sudeste do Brasil têm demonstrado uma certa similaridade no que diz respeito à natureza e cronologia dos eventos mesozóico-cenozóicos (tectônica e sedimentação) na região.

As bacias apresentam arcabouço estrutural configurando semigrabens sobre blocos tectônicos basculados para NW. As falhas normais foram ativas principalmente na borda norte das bacias, onde freqüentemente constituem hoje o limite entre sedimentos e embasamento.

Em todas as bacias, identifica-se uma fácies rudácea basal, atribuída a leques aluviais coalescentes, originados de preferência nas escarpas de falha da borda norte das bacias. Essa fácies rudácea grada vertical e lateralmente para depósitos de sistema fluvial anastomosado, passando em seguida a fluvial meandrante. $\mathrm{Na}$ Bacia de Taubaté, a existência de uma expressiva fácies lacustre (Formação Tremembé) indica presença de condições particulares de represamento e deposição.

Estudos palinológicos em sedimentos das bacias de Resende, Taubaté e São Paulo, e datações K-Ar de derrames de lava na bacia de Volta Redonda indicam idade eocênica superior para pelo menos uma parte do preenchimento das bacias.

As semelhanças do arcabouço estrutural, a similaridade das fácies sedimentares encontradas e o sincronismo observado indicam que as quatro bacias tiveram uma evolução homóloga, ligada aos mesmos processos de distensão regional.

Os dados estruturais disponíveis permitem propor um modelo de evolução relacionado inicialmente aos esforços transicionais, que desenvolveram falhas normais E-NE, ligados aos processos de ruptura continental.

Posteriormente ter-se-iam criado de preferência falhas normais $\mathrm{N}-\mathrm{NE}$ responsáveis pelo barramento da drenagem e início da sedimentação continental.

Esta proposta de evolução geológica é formulada ainda em base interpretativa, mas existem argumentos que lhe dão sustentação. Tendo em vista as implicações no estabelecimento de modelos tectônicos, e de repartição da atividade sísmica potencial, torna-se importante a consideração desses argumentos na proposição de hipóteses as mais coerentes possíveis. Aplicações diretas recaem sobre setores fundamentais, como a interpretação do padrão estrutural de bacias petrolíferas na plataforma continental e previsão de risco sísmico na área emersa.

A modelagem geodinâmica contempla dois modelos diferentes. No momento, procura-se alcançar um que harmonize os dados levantados.

\section{REFERÊNCIAS BIBLIOGRÁFICAS}

ALMEIDA, F.F.M. de - 1958 - Vale do Parafba. In: DEPARTAMENTO NACIONAL da PRODUÇ̃̃O MINERAL. Divisão de Geologia e Mineralogia. Relatório Anual do Diretor. Rio de Janeiro. p. 90-91.

ALMEIDA, F.F.M. de - 1976 - The system of continental rifts bordering the Santos Basin, Brazil. An. Acad. Bras. Ci., Rio de Janeiro, 48 (supl.) : 15-26.

ALMEIDA, F.F.M. de - 1983 - Relações tectônicas das rochas alcalinas mesozóicas da região meridional da Plataforma Sul-Americana. Rev. Bras. Geoc., São Paulo, 13 (3) : 139-158.
ALMEIDA, F.F.M. de et al. - 1980 - Informações geofísicas sobre o oeste mineiro e seu significado geotectônico. An. Acad. Bras. $\mathrm{Ci}$., Rio de Janeiro, 52 (1) : 46-60.

ALMEIDA, F.F.M: de et al. - 1984a - Mapeamento geológico de detalhe de estruturas falhadas em camadas da Formação Itaquaquecetuba e possiveis implicações na estabilidade regional. São Paulo. 76 p. (IPT. Relatório 19 562).

ALMEIDA; F.F.M. de et al. - 1984b - Tectônica da Formação Itaquaquecetuba na Grande São Paulo. In: CONGRESSO BRASILEIRO de GEOLOGIA, 33, Rio de Janeiro, 1984. Anais... Rio de Janeiro, SBG, v. 4, p. 1794-1808. 
AMADOR, E. da S. - 1975 - Estratigrafia e sedimentação da Bacia de Resende, R.J. An. Acad. Bras. Ci., Rio de Janeiro, 47 (supl.) : 181-225.

AMADOR, E. da S. \& CASTRO, M.I.B. de - 1976 - Depósitos neocenozóicos da Bacia de Volta Redonda, R.J. In: CONGRESSO BRASILEIRO de GEOLOGIA, 29, Ouro Preto, 1976. Anais.. Ouro Preto, SBG, v. 1, p. 307-327.

AMARAL, G. et al. - 1966 - Potassium-argon ages of basaltic rocks from Southern Brazil. Geoch. Cosmoch. Acta, 30 :159-189.

AMARAL, G: et al. - 1967 - Potassium-argon ages of alkaline rocks from Southern Brazil. Geoch. Cosmoch. Acta, 31 : 117-142.

ANGELIER, J. \& BERGERAT, F. - 1983 - Systèmes de contraintes et extension intracontinentale. Bull. Centres Rech. Explor. Prod. Elf-Aquitaine, 7 (1) : 137-147.

ANGELIER, J. \& MECHLER, P. - 1977 - Sur une méthode graphique de recherche des contraintes principales également utilisable en tectonique et en seismologie; la méthode des dièdres droits. Bull. Soc. Géol. France, Paris, 7 (6) :1309-1318.

ARTHAUD, F, - 1969 - Méthode de détermination graphique des directions de reccourcissement, d'allongement et intermediaire d'une population de failles. Bull. Soc. Géol. France, Paris, (7) : 729-737.

ASMUS, H.E. - 1978 - Hipótese sobre a origem dos sistemas de zona de fraturas oceânicas/alinhamentos continentais que ocorrem nas regióes sudeste e sul do Brasil. Rio de Janeiro. p. 39-73 (Projeto Remac, 4).

ASMUS, H.E - 1982 - Geotectonic significance of MesozoicCenozoic magmatic rocks in the brazilian continental margin and adjoining emerged area. In: CONGRESSO LATINOAMERICANO de GEOLOGIA, 5, Buenos Aires, 1982. Actas... Buenos Aires. CCDSGLA. v. 3, p. 761-779.

ASMUS, H.E. \& FERRARI, A.L. - 1978 - Hipótese sobre a causa do tectonismo cenozóico na região sudeste do Brasil. Rio de Janeiro. p. 75-88. (Projeto Remac, 4).

ASMUS, H.E. \& GUAZELLI, W. - 1981 - Descrição sumária das estruturas da margem continental brasileira e das áreas oceânicas e continentais adjacentes - Hipótese sobre o tectonismo causador e implicações para os prognósticos do potencial de recursos minerais. Rio de Janeiro. p. 187-269. (Projeto Remac, 9).

BAKER, B.H. \& MORGAN, P. - 1981 - Continental rifting: progress and outlook. Trans. An. Geophys, Union, EOS, 62 585-586.

BERGERAT, F. - 1977 - Le rôle des décrochements dans le liaisons tectoniques entre le Fossé de la Saône et le Fossé Rhénan. Comptes Rendus Sommaires des Séances de la Societé Géologique de France, Paris, (4) : 195-199.

BERGERAT', F. \& CHORWICZ, J. - 1981 - Êtude des images Landsat de la zone transformante Rhin-Saône (France). Geol. Rundschau, Stuttgart, 70 (1) : 354-367.

BJORNBERG, A.J.S. et al. - 1968 - Contribuição ao estudo da bacia de Resende, Rio de Janeiro. Bol. Soc. Bras. Geol., São Paulo, 17 (1) : 65-76.

BULLARD, E.C. et al. - 1965 - Fit of continents around Atlantic. In BLACKETT BULLARD \& RUNCORN (Eds.). A Symposium on continental drift. Royal Soc. London Philos. Trans., Series A, $258: 41-75$.

BURKE, K. \& DEWEY, J.F. - 1973 - Plume generated triple junctions: Key indicators in applying plate tectonics to old rocks. J. Geology. Chicago, 81 (4) :406-433.

CAMPANHA, G.A. da C. et al. - 1985 - Análise do padrão de fraturamento mesozóico-cenozóico de bacias tafrogênicas continentais do Sudeste do Brasil. In: SIMPOSIO REGIONAL de GEOLOGIA, 5, São Paulo 1985. Atas... São Paulo, SBG. (no prelo).

CARNEIRO, C.D.R. et al. - 1976 - Estrutura da Bacia de Taubaté na região de São José dos Campos. In: CONGRESSO BRASILEIRO de GEOLOGIA, 29, Belo Horizonte, 1976. Anais... Ouro Preto, SBG, v. 4, p. 247-256.

COIMBRA, A.M. et al. - 1983 - A formação Itaquaquecetuba: evidências de tectonismo no Quaternário Paulista. In: SIMPOSIO REGIONAL de GEOLOGIA, 4, São Paulo, 1983. Atas... São Paulo, SBG, p. 253-266.

COUTO, C.P. \& MEZZALIRA, S. - 1971 - Nova conceituação geocronológica de Tremembé, Estado de São Paulo, Brasil. An. Acad. Bras. Ci., Rio de Janeiro, 43 (supl.) : 473-488.

FERREIRA, C.S. \& SANTOS, A.S. - 1982 - Novos dados sobre a geocronologia da Formação Tremembé, Vale do Parafba, SP, com base palinológica. An. Acad. Bras. Ci., Rio de Janeiro, 54 (1) : 264 (Resumos).

FERREIRA, F.J.F. - 1982 - Alinhamentos estruturais-magnéticos na região centro-oriental da bacia Paraná e seu significado tectônico. In: INSTITUTO de PESQUISAS TECNOLOGICAS do ESTADO de SÃO PAULO. Geologia da Bacia do Paraná; reavaliação da potencialidade e prospectividade em hidrocarbonetos. São Paulo. p. 143-166. (IPT. Publicação Especial, 12).

HASUI, Y. \& CARNEIRO, C.D.R. - 1980 - Origem e evolução da bacia sedimentar de São Paulo. In: MESA REDONDA: ASPECTOS GEOLOGICOS E GEOTÉCNICOS da BACIA SEDIMENTAR de SÃO PAULO, São Paulo, 1980, p. 5-14. (Publicação Especial SBG).

HASUI, Y. \& PONÇANO, W.L. - 1978 - Organização estrutural e evolução da bacia de Taubaté. In: CONGRESSO BRASILEIRO de GEOLOGIA, 30, Recife, 1978. Anais... Recife, SBG, v. 1, p. 368-381.

HASUI, Y. et al - 1978 - Sobre as bacias tafrogênicas continentais do Sudeste Brasileiro. In: CONGRESSO BRASILEIRO de GEOLOGIA, 30, Recife, 1978. Anais... Recife, SBG, v. 1, p. 368-381.

HASUI, Y. et al. - 1982 - Geologia, tectônica, geomorfologia e sismologia regionais de interesse d̀s usinas nucleares da praia de Itaorna. São Paulo, IPT. 159 p. (IPT. Monografias, 6).

HERZ, N. - 1977 - Timing of spreading in South Atlantic: information from Brazilian alkalic rocks. Geol. Soc. Am. Bull. 88 101-102. Jan

HERZ, N. - 1978 - Basaltic and alkalic rocks of southern Brazil: a review. In: NEWMANN \& RAMBERG (Eds.) Petrology and geochemistry of continental rifts. Boston, Nato Advanced Study Inst. Series Ser. C. Reidel.

KOWSMANN, R.O. et al. - 1982 - Geologia estrutural do Platô de São Paulo. In: CONGRESSO BRASILEIRO de GEOLOGIA 32, Salvador, 1982. Anais... Salvador, SBG. v. 4, p. 1558-1569.

LE PICHON, X. \& HAYES, D.E. - 1971 - Marginal offsets, facture zones and the early opening of the south Atlantic. J. Geophys. Res. 76 (26) :6283-6293.

LIMA, M.R. de \& AMADOR, E. da S. - 1983 - Análise palinológica de sedimentos da Formação Resende, Terciário do Estado do Rio de Janeiro, Brasil. In: CONGRESSO BRASILEIRO de PALEONTOLOGIA, 8, Rio de Janeiro, 1983. Anais... Rio de Janeiro, SBP, (no prelo).

LIMA, M.R. de \& DINO, R. - 1985 - Palinologia de amostras da bacia de Bonfim, Terciário do Estado de São Paulo, Brasil. An. Acad. Bras. Ci. (no prelo).

LIMA, M.R. de et al. - 1983 - Etude palynologique de la Formation Tremembé, tertiaire du basin de Taubaté, État de São Paulo, Brésil, d'aprèsles échantillons du sondage no 42 du CNP. In: CONGRESSO BRASILEIRO de PALEONTOLOGIA, 8, Rio de Janeiro, 1983. Anais... Rio de Janeiro, SBP, (no prelo).

MARSH, J.R. - 1973 - Relationships between transform directions and alkaline igneous rocks lineaments in Africa and South America. Earth Planet. Sci. Let. $18: 317-323$.

MELO, M.S. de - 1984 - Géologie du bassin de Resende et contribution à l'évolution du Système de Rift du SE du Brèsil. Marseille, Université d'Aix-Marseille I et II. 62 p.

MELO, M.S. de et al. - 1983 - Estudos geológico-tectônicos na Bacia de Resende (RJ) e sedimentos terciários da área de Volta Redonda (RJ) e Bacia de Taubaté (área de Cruzeiro, SP). São Paulo, DMGA, 2v. (IPT. Relatório, 17 737).

MEZZALIRA, S. - 1962 - Novas ocorrências de vegetais fósseis no Estado de São Paulo. OIGG., São Paulo, IGG (15) : 73-91.

MIOTO, J.A. - 1984 - Mapa de risco sísmico do sudeste brasileiro. São Paulo (IPT. Monografias, 10. Publicação, 1563).

MORAES REGO, L.F. de - 1930 - A geologia do petróleo no Estado de São Paulo. Bol. Serv. Geol. Min. do Brasil, Rio de Janeiro, (46) : 1-110.

MORAES REGO, L.F. de - 1932 - Notas sobre a geomorfologia de São Paulo e sua gênese. São Paulo, Instituto Astronômico Geofísico. $28 \mathrm{p}$.

PEREIRA MARTINS Jr., P. - 1976 - Volcanisme et rhegmagenèse pré-atlantique du continent afro-américain et géochimie des vases pélagiques de l'ocean Atlantique. (Thèse pour l'obtention du diplôme de Docteur. Univ. Pierre et Marie Curie, Paris 6).

PONTE, F.C. \& ASMUS, H.E. - 1976 - The brazilian marginal basins: current state of knowledge. An. Acad. Bras. Ci., Rio de 
Janeiro, 48 (supl.) : 215-239.

RICCOMINI, C. et al. - 1983 - Sobre a ocorrência de um derrame de ankaramito na Bacia de Volta Redonda (RJ) e sua importância na datação das bacias tafrogênicas continentais do sudeste brasileiro. In: SIMPOSIO REGIONAL de GEOLOGIA, 4, São Paulo, 1983. Bol. Resumos... São Paulo, SBG, p. 23-24. SADOWSKI, G.R. \& DIAS NETO, C.M. - 1981 - O lineamento sismo-tectônico de Cabo Frio. Rev. Bras. Geoc., -São Paulo, 11 (4) : 209-212.

SADOWSKI, G.R. \& DIAS NETO, C.M. - 1981 - O lineamento sismo-tectônico de Cabo Frio. Rev. Bras. Geoc., São Paulo, 11 (4) : 209-212.

SCHOBBENHAUS FILHO, C. et al. - 1981 - Mapa geológico do Brasil e da área oceânica adjacente incluindo os depósitos minerais; escala $1: 2.500 .000$. Brasilia, DNPM.

SENGOR, A.M.C. \& BURKE, A. - 1978 - Relative timing of rifting and volcanism on arth and its tectonic implications. Geophys. Res. Let. 5 (6) :419-421.

SUGUIO, K. - 1969 - Contribuição à geologia da Bacia de Taubaté; Vale do Paratba, Estado de São Paulo. São Paulo. 106 p. (Tese de Doutoramento. Faculdade de Filosofia Ciências e Letras. USP).

SUGUIO, K. - 1971 - Estudo dos troncos de árvores "linhitificados" dos aluviões antigos do rio Pinheiros (SP): significados geocronológico e possivelmente paleoclimático. In: CONGRESSO BRASILEIRO de GEOLOGIA 25, São Paulo, 1971. Anais... São Paulo, SBG. v. 1, p. 63-69.

SUGUIO, K. - 1980 - Stntese dos conhecimentos sobre a sedimentação da Bacia de São Paulo. São Paulo. p. 25-34. (Publ. Especial SBG).
SUGUIO, K. \& MARTIN, L. - 1976 - Brazilian coastline quaternary formations the States of São Paulo and Bahia littoral zone evolutive schemes. An. Acad. Bras. Ci. 48 (supl.) : 325-334.

TAPPONNIER, P. \& VARET, J. - 1974 - La zone de Mak'arrasou en Afar: un équivalent emergé des failles transformantes. C.R. Acad. Sci., Paris, 278 (2) : 209-212.

TCHALENKO, J.S. - 1970 - Similarities between shear zones of different magnitudes. Geol. Soc. Am. Bull., Boulder, 81 (6) : $1625-1640$.

TCHALENKO, J.S. \& AMBRASYS, N.N. - 1970 - Structural analyses of the Sashte Bayas (Iran) earthquake features. Geol. Soc. Am. Bull., Boulder, 81 (1) : 41-60.

ULBRICH, H.H.G.J. \& GOMES, C. de B. - 1981 - Alkaline rocks from continental Brazil, Earth Sci. Reviews, Amsterdam, 17 : 135-154.

UNIVERSIDADE de BRASILIAA. 1979. Convênio FUB/CESP. Relatório no 13. Brasília, 15 p.

VIEIRA, A.J. - 1973 - Geologia do centro e nordeste do Paraná e centro-Sul de São Paulo. In: CONGRESSO BRASILEIRO de GEOLOGIA, 27, Aracaju, 1973. Anais..., Aracaju, SBG, v. 3, p. 259-277.

WICKERT, W.Q. - 1974 - Contribuição ao estudo da paleontologia da bacia de Taubaté, Estado de São Paulo. Rio de Janeiro (Dissertação de mestrado. Universidade Federal do Rio de Janeiro. Instituto de Geociências).

MANUSCRITO

Recebido em 19 de agosto de 1985 Revisão aceita em 19 de novembro de 1985

A ciência busca reduzir as conexões descobertas ao menor número (possível) de elementos independentes. 